\title{
PRESERVATION PROCESSES
}

\section{Protein under glass}

Proteins are typically preserved in the form of dehydrated powders to avoid their degradation or the growth of microbes that can occur in solution. Such powders are typically obtained by freeze-drying, but some proteins can be damaged during the process. Now, using an organic solvent (decanol) as drying agent, David Needham and coworkers at Duke University in the USA have successfully dehydrated a protein (lysozyme) to form beads of controllable size through a simple glassification procedure (pictured; Biophys. J. 98, 1075-1084; 2010)

In aqueous solutions, biological molecules are closely surrounded by hydration water molecules that are more difficult to remove than those of the bulk solution, and which keep the molecules apart. When small droplets of an aqueous lysozyme solution were

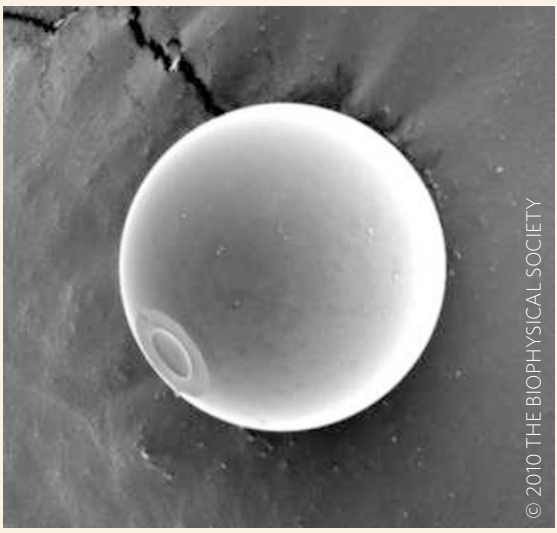

structure. On re-hydration, the lysozyme recovered most of its activity.

Using a packing model, the researchers determined the level of protein hydration, and therefore the separation distance between the lysozyme molecules, from the water activity measured in decanol (its 'concentration' in the non-ideal mixture). This means that by adjusting the water activity in the drying solvent, they were able to control the final protein concentration, and thus the size of the resulting glassy beads. This drying method was also faster and cheaper than the freeze-drying process, showing great promise for biological applications.

added into a decanol solution, all the bulk and hydration water molecules dissolved into the organic solvent within minutes. This process was too fast for the protein to crystallize and instead it arranged into microbeads with a glassy, amorphous

\section{ANNE PICHON}

The original version of this story first appeared on the Research Highlights section of the Nature Chemistry website. 